$$
\operatorname{Conf}_{\text {LBL-28974 }}-901105-129
$$

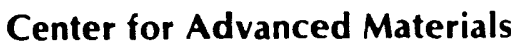

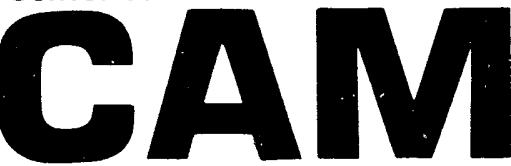

\section{Received
ост 161991}

Presented at the F. Weinberg Symposium on Solidification Processes, Hamilton, Ontario, August 26-29, 1990, and to be published in the Proceedings

\section{Vertical Bridgman and Gradient Freeze Growth of III-V Compound Semiconductors}

E.D. Bourret

July 1990

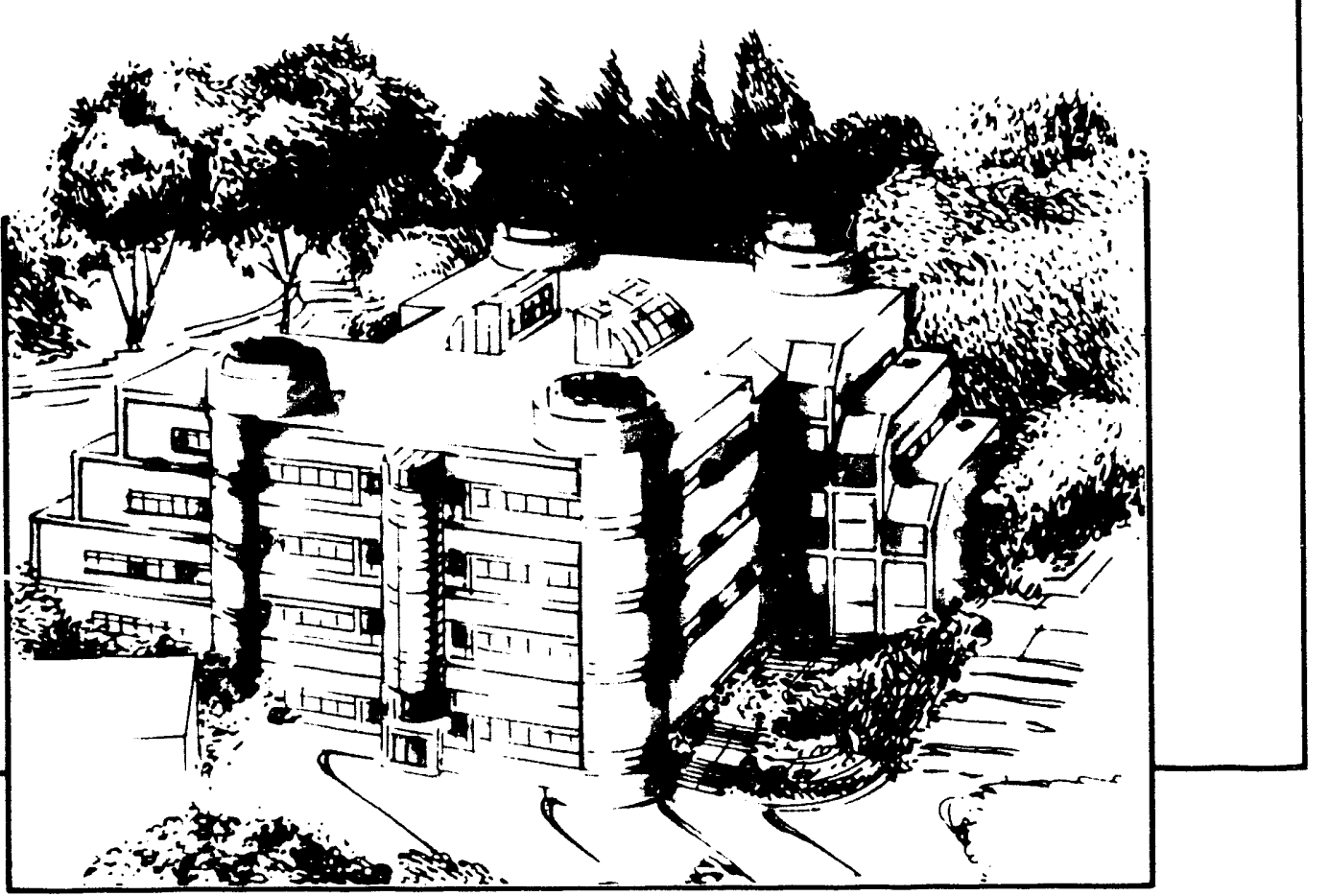

\section{Materials and Chemical Sciences Division}

\section{Lawrence Berkeley Laboratory - University of California}

ONE CYCLOTRON ROAD, BERKELEY, CA 94720 •(415) 486-4755

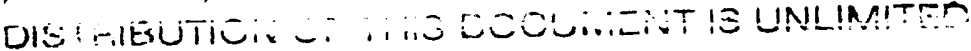




\section{DISCLAIMER}

This document was prepared as an account of work sponsored by the United States Government. Neither the United States Government nor any agency thereof, nor The Regents of the University of California, nor any of their employees, makes any warranty, express or implied, or assumes any legal liability or responsibility for the accuracy, completeness, on usefulness of any information, apparatus, product, or process discl ssed, or represents that its use would not infringe privately owned rights. Reference herein to any specific commercial product, process, or service by its trade name, trademark, manufacturer, or otherwise, does not necessarily constitute or imply its endorsement, recommendation, or favoring by the United States Government or any agency thereof, or The Regents of the University of California. The views and opinions of authors expressed herein do not necessarily state or reflect those of the United States Government or any agency thereof or The Regents of the University of California and shall not be used for advertising or product endorsement purposes.

Lawrence Berkeley Laboratory is an equal opportunity employer. 
LBL- -28974

DE92 000893

\title{
VERTICAL BRIDGMAN AND GRADIENT FREEZE GROWTH OF III-V COMPOUND SEMICONDUCTORS
}

\author{
E.D. Bourret \\ Center for Advanced Materials, Materials Sciences Division \\ Lawrence Berkeley Laboratory \\ 1 Cyclotron Road, Berkeley, CA 94720
}

This report has been reproduced directly from the best available copy.

This work was supported by the Director, Office of Energy Research, Office of Basic Energy Sciences, Materials Sciences Division of the U.S. Department of Energy under Contract No. DE-AC03-76SF00098. 


\title{
VERTICAL BRIDGMAN AND GRADIENT FREEZE GROWTH OF III-V COMPOUND SEMICONDUCTORS
}

\author{
E.D.Bourret \\ Center for Advanced Materials (2-200) \\ Materials and Chemical Science Division \\ Lawrence Berkeley Laborotory \\ University of California \\ Berkeley CA 94720
}

\begin{abstract}
:
Major improvements in the structural and electrical perfection of single crystals of III-V compound semiconductors have been achieved by using new vertical Bridgman-type and vertical gradient freeze techniques. A general review of experimental set-ups used for growth of large diameter crystals of GaP, InP and GaAs is presented. Crystals properties and characteristic features are discussed to illustrate advantages and disadvantages of the vertical Bridgman-type growth techniques.
\end{abstract}

\section{Introduction:}

The Czochralski technique (1) has been the preferred method for growth of many semiconductor single crystals since 1950 when it was first used for growth of single crystals germanium. The first successful growth of $\mathrm{GaAs}$ single crystals was carried out using a modified Czochralski technique, the Gremmelmeier technique (2). In this technique, a sealed system with magnetic coupling for the rotation and pulling mechanisms is used to maintain an arsenic vapor pressure in the chamber which prevents decomposition of the GaAs melt. Mullin et al.(3) in 1965 developed the liquid encapsulation technique, an adaptation of the work of Metz et al. (4) for growth of III-V compounds. The Czochralski (LEC) technique quickly became the industry standard for production of semi-insulating GaAs particularly after it was demonstrated that PBN crucibles could be used to produce undoped semi-insulating crystals.

In the mean time, the horizontal gradient freeze and horizontal Bridgman techniques were widely used to grow doped conducting crystals as well as chromium-doped semi-insulating crystals. It was assumed that the horizontal configuration was necessary in order to limit confinement of the crystal and to allow free expansion of the crystal upon solidification. Based on this assumption, the vertical gradient freeze and vertical Bridgman techniques were not fully investigated for growth of III-V compounds, despite encouraging early results obtained for GaP as reported in a review of crystal growth techniques for II-VI and III-V compounds by Fischer (5). Fischer describes vertical Bridgman / gradient freeze growth of $\mathrm{GaP}$ in a pressure-relieved ampoule using pyrolytic boron nitride crucibles (figure 1). Blum et al. (6) successfully grew $1.5 \mathrm{~cm}$ diameter $\mathrm{GaP}$ single crystals in pyrolytic boron nitride crucibles by the liquid encapsulated vertical gradient freeze technique (LE-VGF). These authors concluded that "crystals grown by the LEVGF technique are appreciably less strained, lower in dislocation density, excellent in diameter control and easier to grow than the conventional LEC GaP". Woodbury (7) tried to scale-up the LE-VGF technique for seeded growth of up to $35 \mathrm{~mm}$ diameter GaP crystals. Difficulties in reproducibly growing single crystals were encountered due to spurious nucleation at the crystal/seed-melt junction. Several recommendations were presented to solve these problems and 


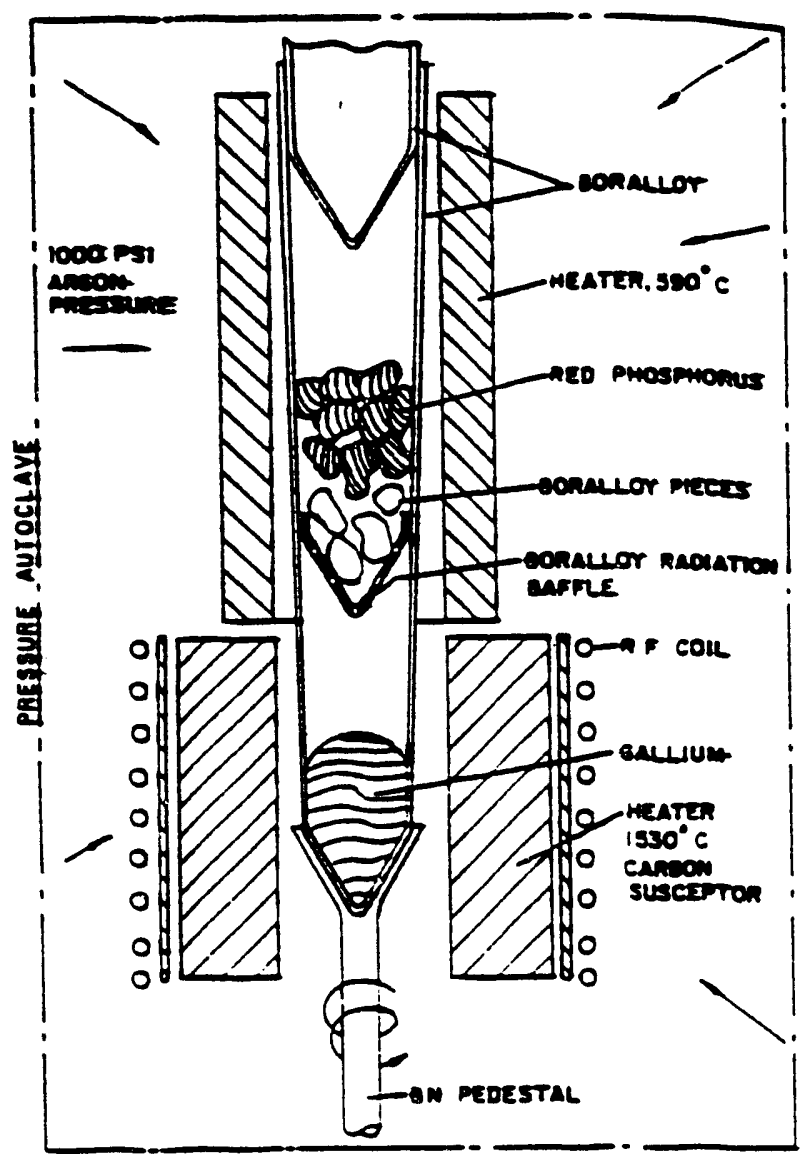

Figure 1. GaP synthesis and crystal growth demontable pyrolytic $\mathrm{BN}$ ampoule (reproducof fig. 7 from ref. 5). the author stated that this technique might be the easiest way to grow large, strain-free ingots of materials with high vapor pressure directly from their melt as long are they are chemically compatible with molten boron oxide.

Chang et al.(8) have used GaAs to illustrate the flexibility of the vertical gradient freeze technique in terms of control of the growth parameters. They used high freezing rates to solidify unseeded ingots $10 \mathrm{~mm}$ diameter and 17 $\mathrm{cm}$ long in silica crucibles and concluded: "we see no reason why large diameter useful $\mathrm{GaAs}$ cannct be produced by this technique, at least at low doping levels". It was only in 1986 that the first study of growth of high quality III-V crystals of large diameter was published (9) which started a renewed interest in the technique.

In this paper, a review of the experimental set-ups used for growth of large diameter crystals of $\mathrm{GaP}$, InP and $\mathrm{GaAs}$ is presented. Crystal properties and characteristic features are discussed to illustrate advantages and disadvantages of the vertical Bridgman-type techniques.

\section{GaP:}

$\mathrm{GaP}$ was the first III-V compound to be grown by the vertical gradient freeze technique (5). in a Crystals up to $5 \mathrm{~cm}$ diameter have now been tion obtained. The largest crystals (9) were grown in a water-cooled, stainless steel lined pressure vessel very similar to the chamber first described

by Fischer (5). The chamber assembly is shown in figure 2. Two resistance heaters were used in the vessel. The upper heater (graphite picket-fence) heats a bottom seeded PBN crucible which contains the GaP charge and is used to control the directional solidification process. The lower heater is used to control the temperature of a phosphorus reservoir which provides regulation of the vapor pressure of phosphorus above the melt and prevent its decomposition. The crucible and phosphorus source are placed in a PBN container with a hot-pressed boron nitride cap. This container can be moved vertically up and down and can be rotated during growth. The paper does not specify if these features where used during growth. The phosphorus loss through the cap appears to be small enough that the required partial pressure of phosphorus can be maintained during growth. The axial temperature gradients during growth were about $40^{\circ} \mathrm{C} / \mathrm{cm}$ over the solid and about $8^{\circ} \mathrm{C} / \mathrm{cm}$ over the melt. The pressure of the chamber was maintained at $65 \mathrm{~atm}$ during growth. The crystals grown were $1300 \mathrm{~g},<111\rangle$ seeded and either sulfur or tellurium n-type doped. The dopant concentrations are not stated in the publication. The main feature of these crystals was low dislocation densities ranging from 800 to $2000 / \mathrm{cm}^{2}$. Green light emitting diodes (LED) made by liquid phase epitaxy on wafers from these low dislocation density VGF substrates were $23 \%$ more efficient than LEDs made on LEC substrates.

\section{InP:}

The same furnace as described for $\mathrm{GaP}$ was used to grow large diameter InP crystals (9.10). The axial temperature gradients during growth were mentioned to be lower than for GaP. 


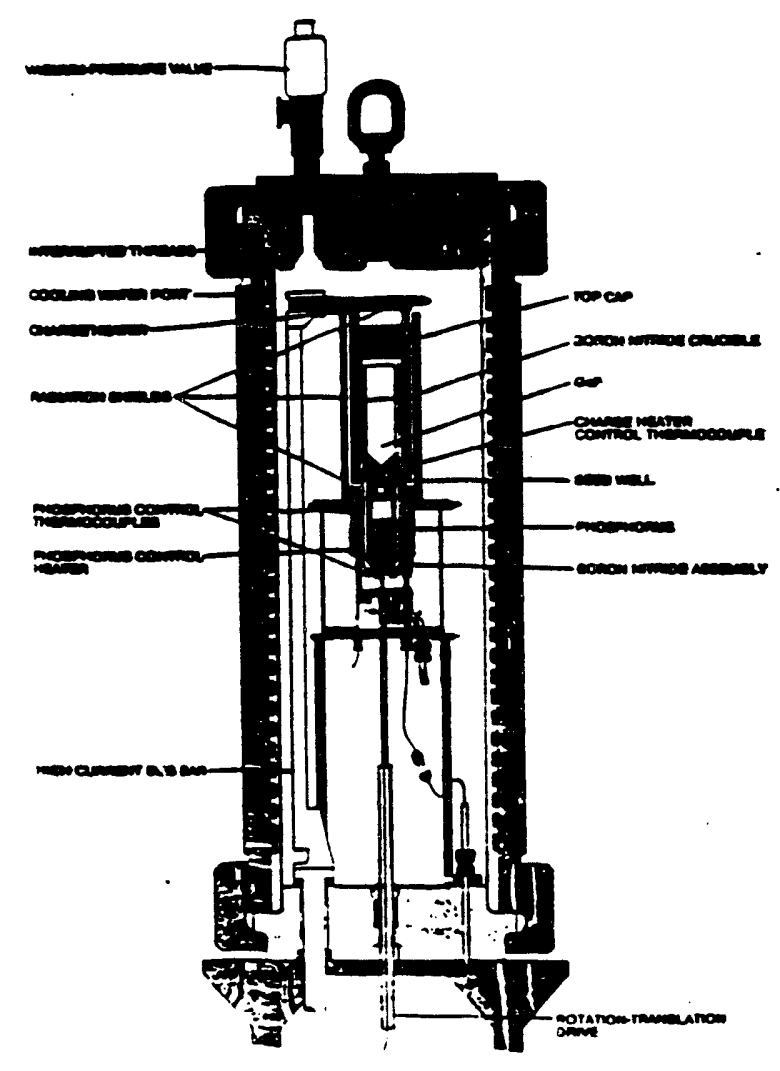

Figure 2. Cross sectional view of vertical gradient freeze crystal growth equipment as configured for $\mathrm{GaP}$ ( reproduction of fig.1 from ref. 9).

Figure 3. (a) Temperature profile along the axis of the load: experimental (dashed lines) and numerical (full line) results (reproduction of fig. 11 from ref.13),

(b) Temperanure field throughout the furnace: the increment is $100 \mathrm{~K}$ ( $335 \mathrm{~K}$ ) for the global view while the increment is $10 \mathrm{~K}$ in the load $(1 \mathrm{~K}$ for dashed line), (reproduction of fig. 12 from ref. 13).

(a)
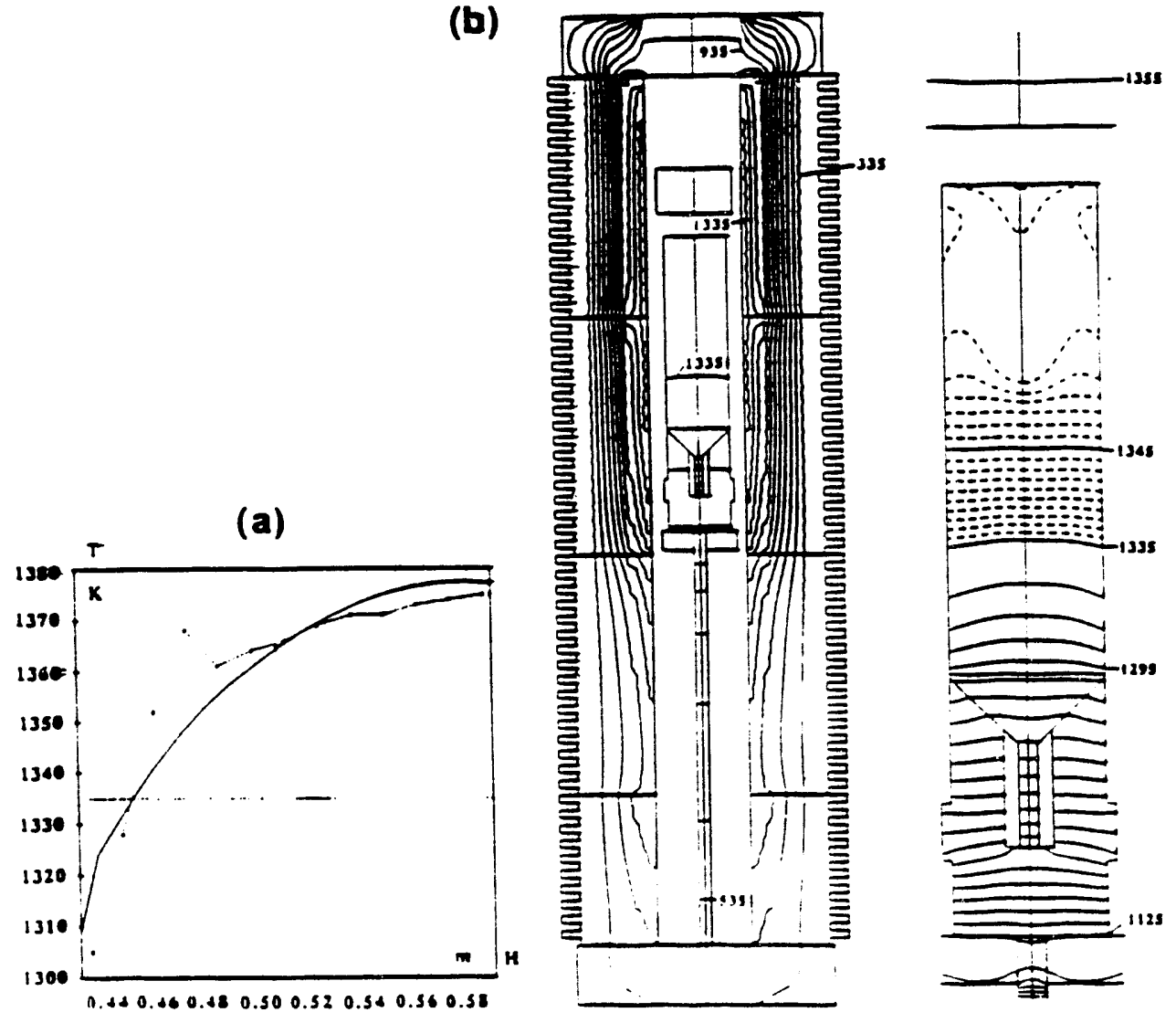
The pressure of the chamber was maintained at $27.5 \mathrm{~atm}$ during growth. The grown crystals were $750 \mathrm{~g},<111\rangle$ seeded and sulfur doped in the range $2 \times 10^{17}$ to $5 \times 10^{18} / \mathrm{cm}^{3}$. The average dislocation density is about $350 / \mathrm{cm}^{2}$ and is not affected by the dopant concentration in the range used. The low level of uniformly distributed dislocations and the absence of slip lines at the periphery of the wafers indicate solidification and cooling under very low thermal stresses. The electrical characteristics reported were similar to those of LEC crystals.

Monberg et al. (11) designed a dynamic gradient freeze furnace for growth of $50 \mathrm{~mm}$ diameter InP. The furnace has 23 heating zones grouped into four sections. The pressure vessel which contains the heating elements can be operated under up to 1500 psi pressure. The crystals grown in PBN crucibles with boron oxide encapsulation were $550 \mathrm{~g},<111>$ seeded undoped. The dislocation density lies in the range $500-1000 / \mathrm{cm}^{2}$. The crystals were n-type with a carrier concentration in the $3 \times 10^{15} / \mathrm{cm}^{3}$ range and with mobilities comparable to those of crystals grown by the LEC technique. Monberg et al. (12) also obtained zinc doped p-type InP, 50 mm diameter, with dislocation density in the range $300-1200 / \mathrm{cm}^{2}$ for a carrier concentration between 1 and $5 \times 10^{17} / \mathrm{cm}^{3}$. The previous studies, however, show that InP grown confined in pyrolytic boron nitride crucibles has a strong tendency to twin.

A global simulation of Monberg's furnace was developed by Crochet et al. (13). The model includes coupling between the various heat transfers by conduction and radiation, latent heat of solidification and natural convection in the melt and the furnace is realistically represented by a finite element mesh. Comparison of the calculated axial temperature profile and measured profiles in a dummy load of boron nitride are in relatively good agreement (figure 3a). The calculated isotherms in the furnace are reproduced in figure $3 \mathrm{~b}$. The crystal-melt interface is slightly convex at the altitude shown. Unfortunately, the experimental interface shapes are not shown for comparison with the calculated shapes.

\section{GaAs:}

As mentioned in the introduction, the first use of a vertical gradient freeze technique for solidification of GaAs was reported by Chang et al. (7). This study was not aimed at producing high quality large diameter single crystals but indicated that the technique could be used for that purpose. It is again in the paper of Gault et al. (9) that results on the first large diameter (50 $\mathrm{mm}$ ) GaAs single crystals grown by a seeded VGF technique were reportcd. The growth conditions (axial temperature gradients, pressure and growth rates) were not reported. The crystals grown were $1200 \mathrm{~g},<100>$ seeded and silicon doped in the range $3 \times 10^{17}$ to $3 \times 10^{18} / \mathrm{cm}^{3}$. The average dislocation density was reported to be about $450 / \mathrm{cm}^{2}$ for a dopant concentration of about $1.5 \times 10^{18} / \mathrm{cm}^{3}$. The disiocation density increases significantly when the cooling rate is $100^{\circ} \mathrm{C} / \mathrm{h}$. Clemans et al. (14) subsequently published results on $75 \mathrm{~mm}$ diameter undoped semi-insulating GaAs using the Gault technique. The average dislocation density is about $2500 / \mathrm{cm}^{2}$ and exhibits the four-fold symmetry pattern induced by thermal stress during growth. Crystals with undetectable $\left(<10^{14} / \mathrm{cm}^{3}\right)$ carbon concentration have a very high resistivity $\left(>10^{8} \Omega \mathrm{cm}\right)$ and crystals with a carbon concentration of $2 \times 10^{15} / \mathrm{cm}^{3}$ at the seed end and $2 \times 10^{14} / \mathrm{cm}^{3}$ at the tail end have a lower resistivity (ranging from $2 \times 10^{7} \Omega \mathrm{cm}$ at the seed end to $7 \times 10^{7} \Omega \mathrm{cm}$ at the tail end). The variations in EL 2 concentrations are $25 \%$, about half of what they are in LEC crystals. The crystals exhibit mobilities of about $7000 \mathrm{~cm}^{2} / \mathrm{Vs}$.

Abernathy et al. (15) described a VGF system in which the PBN crucible is located in a sealed quartz tube. The crystals grown were $400 \mathrm{~g}$ to $1000 \mathrm{~g}, 50 \mathrm{~mm}$ diameter, $<100>$ seeded, undoped and indium-doped at $2 \times 10^{19} / \mathrm{cm}^{3}$. The average dislocation density varies from $2000 / \mathrm{cm}^{2}$ at the seed end to $6000 / \mathrm{cm}^{2}$ at the tail end for undoped crystals. The dislocation patterns show strong lineage features indicative a growth under significant thermal stresses. Semiinsulating crystals with resistivities $>10^{7} \Omega \mathrm{cm}$ were obtained by addition of gallium oxide to the charge. These crystals have a dominating deep level defect at $0.5 \mathrm{eV}$. 


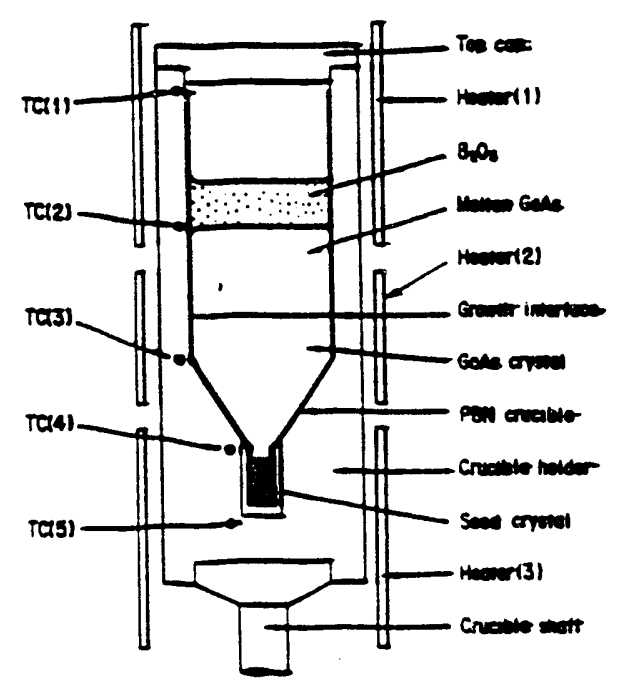

Figure 4. A schematic representation of the VB apparatus used to grow a single crystal (reproduction of fig. 1 from ref. 13).
Hoshikawa et al.(16) have used a liquid encapsulated vertical Bridgman technique (LEVB) for growth of $75 \mathrm{~mm}$ diameter crystals (figure 4). Three graphite heaters are used to control the temperature profile. The crystals grown were $1700 \mathrm{~g},<100\rangle$ seeded. About $200 \mathrm{~g}$ of boron oxide was placed above the GaAs to encapsulate the melt and an argon pressure of $8 \mathrm{~kg} / \mathrm{cm}^{2}$ was maintained in the furnace. The crucible lowering rate was $3 \mathrm{~mm} / \mathrm{h}$ and they estimated the actual growth rate to be about twice that value. A rotation rate of $2 \mathrm{cpm}$ was used during growth. Undoped semi-insulating crystals have dislocation densities ranging from 5000 to $40000 / \mathrm{cm}^{2}$. The electrical characteristics were reported similar to those of undoped semiinsulating LEC crystals. The authors stated three critical issues for reproducible growth: 1) to insure proper seeding by using a seed well of slightly larger diameter than the seed, 2) to have a continuous layer of boron oxide between the LEcrucible and the GaAs, 3 ) to prevent cracking by keeping a relatively uniform temperature of GaAs distribution in the crystal during cooling.

We have grown GaAs single crystals, 37,50 and $62.5 \mathrm{~mm}$ in diameter, by the dynamic gradient freeze technique (17). Both quartz and pyrolytic boron nitride crucibles have been used successfully. Figure 5 is a schematic of the experimental arrangement. The sealed ampoule configuration is very similar to the one used by Abernathy et al.(15). The ampoule support structure and the temperature control, however, are significantly different. The smail diameter part of the quartz ampoule that forms the arsenic reservoir is surrounded by a hot-pressed Boron Nitride (BN) cylinder which acts as a heat-pipe. A thermal gradient of $10^{\circ} \mathrm{C} / \mathrm{cm}$, as measured by the control thermocouples on the outside of the quartz ampoule, is maintained over the solid side of the crystal-melt interface. Very shallow axial thermal gradients are maintained over the melt: $1.2^{2} \mathrm{C} / \mathrm{cm}$ within $5 \mathrm{~cm}$ of the interface and isothermal zone above that region. Growth rates of 3,4 , and $5 \mathrm{~mm}$ per hour have been used. After growth the crystals are cooled at $1^{\circ} \mathrm{C} / \mathrm{min}$ down to $900^{\circ} \mathrm{C}$ then at $2^{\circ} \mathrm{C} / \mathrm{min}$ down to room temperature. Using very shallow temperature gradients over the melt and slow growth rates, the crystal-melt interface can be maintained flat over about $75 \%$ of the diameter. Through control of stoichiometry and with a th mal environment designed to reduce thermal stresses, about $50 \%$ of the crystals have a dislocation density of less than $1,000 / \mathrm{cm}^{2}$.

We have used total liquid encapsulation with $\mathrm{B}_{2} \mathrm{O}_{3}$ to grow $50 \mathrm{~mm}$ diameter $\mathrm{GaAs}$ single crystals in PBN crucibles in a vertical gradient freeze configuration (18). The $\mathrm{B}_{2} \mathrm{O}_{3}$ layer efficiently prevents wetting of the crucible by the GaAs charge. The effect of the water content of $\mathrm{B}_{2} \mathrm{O}_{3}$ on the structural and electrical characteristics of the crystals was investigated. Water vapor can be trapped between the crystal and the crucible affecting the surface morphology of the crystals but not its crystalline perfection.

Numerous theoretical heat transfer analyses of the vertical Bridgman- Stockbarger design have appeared in the literature in the last fifteen years. Most of them were directed toward the understanding of a simple one or two zone design for growth of germanium. Brown recently reviewed the main concepts and results of these analyses (19). Kim et al. analyzed the effect of a magnetic field applied during VB growth of doped germanium (20) and modeled growth of the more complex system HgCdTe also grown in a vertical Bridgman configuration (21). These fundamental studies are mentioned here because the results help the understanding of the process and are useful for growth of $\mathrm{GaAs}$ as well. Kim (22) used the same concepts to model growth of $\mathrm{GaAs}$ in a closed ampoule. The low thermal conductivity of $\mathrm{GaAs}$ is responsible for a concave crystal-melt interface. Such analyses as well as the global analysis mentioned for InP (13) should 

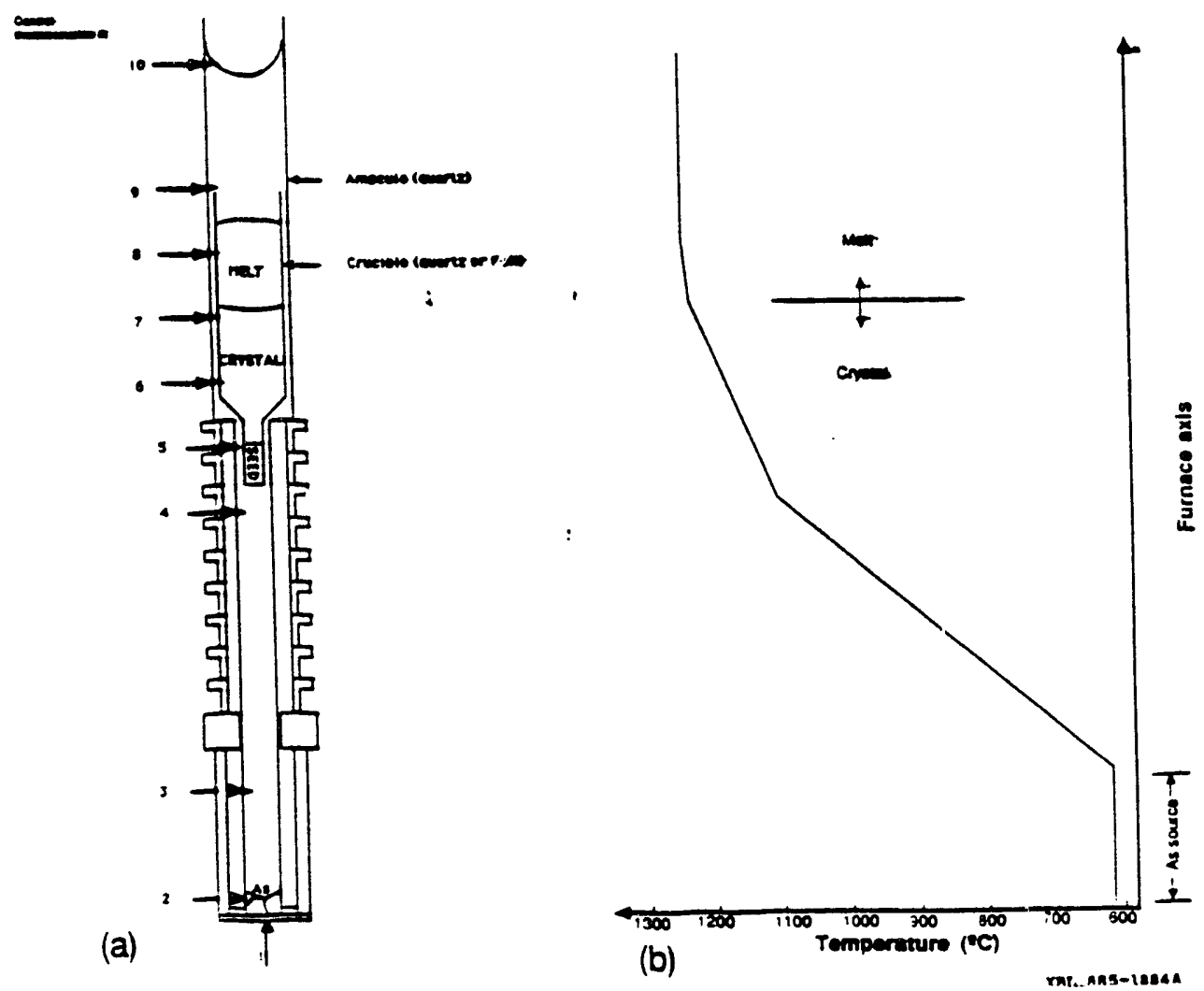

Figure 5: (a) Schematic of the experimental set-up showing the growth ampoule and the position of the control thermocouples

(b) temperature profile as measured on the outside of the growth arnpoule during growth.

be done for each experimental set-up since they have reached a level of accuracy which allows optimization of the growth process.

\section{Summary:}

It has now clearly been demonstrated that vertical Bridgman-type techniques are a viable technique for growth of III-V compounds. These techniques involve a relatively simple technology compared to the Czochralski technique. More importantly crystals can be grown with excellent diameter control which reduces waste from subsequent grinding operations. There appears to be no theoretical limits to the size, length and diameter of crystals which can be grown. However in very large systems the control of heat flows will be more difficult due to the very low thermal conductivities of the III-V compounds. Since the main feature of the technique is growth in a crucible, it is mandatory that there be no reaction between the crucible and the charge. Chemical reactions induce contamination of the melt which can be detrimental to the electrical properties of the crystal. Sticking between the crucible and the charge creates random nucleation sites on the crucible wall and generation of low angle grain boundaries and twins. Pyrolytic boron nitride appears well suited for growth of GaP. Total liquid encapsulation with boron oxide is necessary for reproducible growth of $\mathrm{GaAs}$. Total liquid encapsulation also provides an efficient barrier to irmpurity contamination, in particular silicon impurities arising from partial decomposition of quartzware that might be present in the furmace. Reproducible growth of fully single crystals of InP has not yet be demonstrated even though very promising results have been obtained. 
This work was supported by the Director, Office of Iinergy Research, Office of Basic Energy Sciences, Materials Science Division, of the U.S. Department of Energy under Contract No. DE-AC03-76SF00098.

\section{References:}

(1) J.Czochralski, Z.Phys.Chem. 92 (1918) 219.

(2) R.Gremmelmeier, Z.Naturforsch.,11a (1956) 511.

(3) J.B. Mullin, B.W.Straughan and W.S.Brickell, J. Phys. Chem. Solids 26 (1965) 782.

(4) E.P.A.Metz, R.C.Miller and R.Mazelsky, J.Appl. Phys., 33 (1962) 2016.

(5) A.G.Fischer, J.Electrochem.Soc., 117, No2 (1970) 41C.

(6) S.E.Blum and R.J.Chicotka,J.Electrochem.Soc. 120 (1973) No.4, 588.

(7) H.H.Woodbury, J.of Crystal Growth 35 (1976) 49.

(8) C.E.Chang, V.F.S.Yip and W.R.Wilcox, J.of Crystal Growth 22 (1974) 247.

(9) W.A.Gault, E.M.Monberg and J.E.Clemans, J.of Crystal Growth 74 (1986) 491.

(10) E.M.Monberg, W.A.Gault, F.Simchock and F.Dominguez, J.of Crystal Growth 83 (1987) 174.

(11) E.M.Monberg, H.Brown and C.E.Bonner, J.of Crystal Growth 94 (1989) 109.

(12) E.M.Monberg, P.M.Bridenbaugh, H Brown, and R.L.Barns, J. of Electronic Materials 18 (1989) 549.

(13) M.J.Crochet, F.Dupret, Y.Rickmans, F.T.Geyling and E.M.Monberg, J.of Crystal Growth 97 (1989) 173.

(14) J.E.Clemans and J.H.Conway, in: Proc. 5th Conf. on Semi-Insulating III-V Materials, Malmö, Sweden June 1988, Eds. J.Grossmann and L.Lebedo (Hilger,Bristol,1988).

(15) C.R.Abernathy, A.P.Kinsella, A.S.Jordan, R.Caruso, S.J.Pearton, H.Temkin and H.Wade, J.of Crystal Growth 85 (1987) 106.

(16) K.Hoshikawa, H.Nakanishi H.Kohda and M.Sasaura, J.of Crystal Growth 94 (1989) 643.

(17) E.D. Bourret, M.L. Galiano, R.D. Mih, J.B. Guitron and E.E. Haller, J.Crystal Growth (1990) in press.

(18) E.D.Bourret and E.Merk in: Proc. 8th American Conf. on Crystal Growth, Vail, Colorado July 1990, to be published in J. Crystal Growth.

(19) R.A.Brown, AIChE J. 34 (1988) 881.

(20) D.H.Kim, P.M.Adornato and R.A.Brown, J.of Crystal Growth 89 (1988) 339.

(21) D.H.Kim and R.A.Brown, J.of Crystal Growth 96 (1989) 609.

(22) D.H.Kim, PhD Thesis, Department of Chemical Engineering, Massachusetts Institute of Technology (1990). 

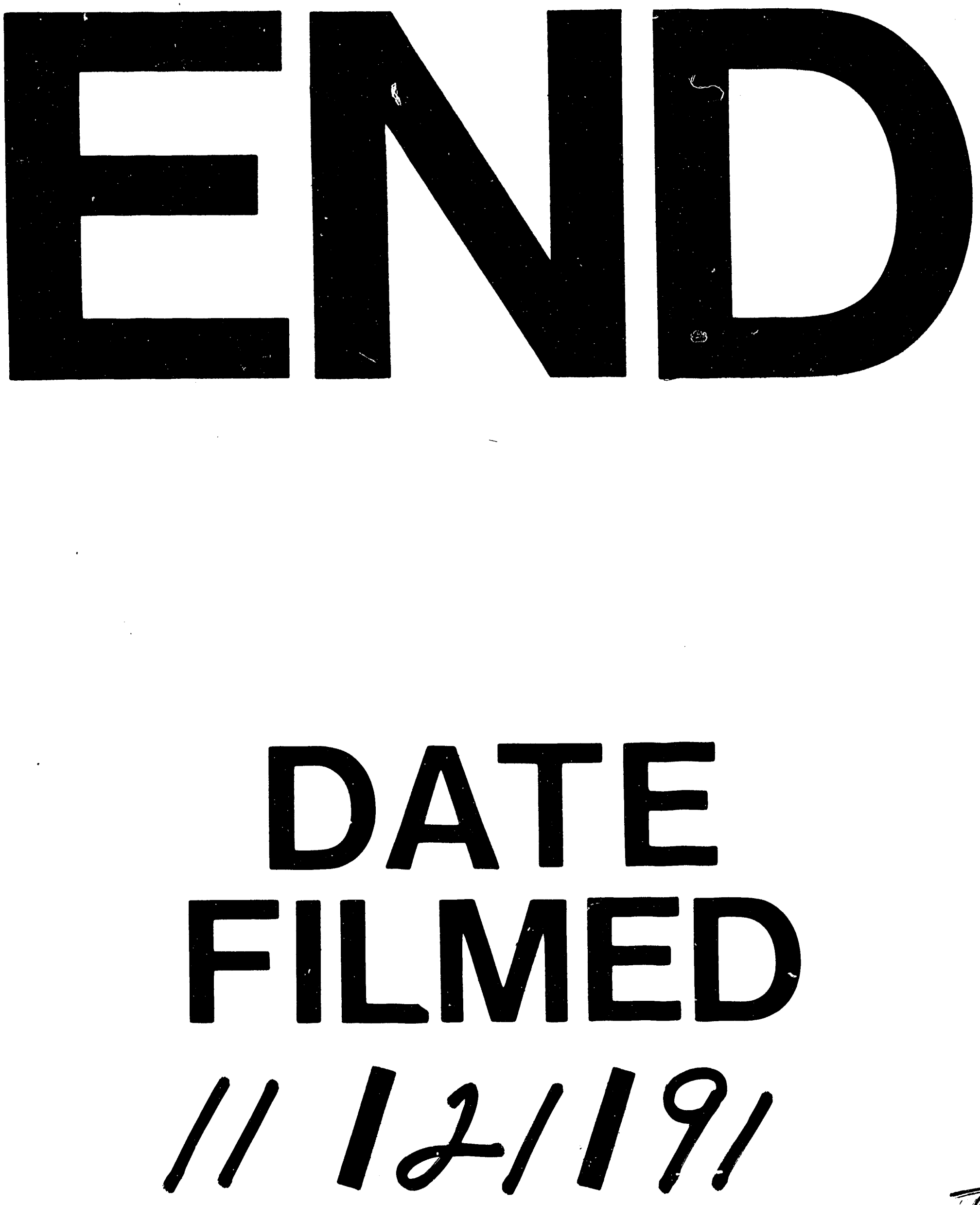

II 
